\title{
Ten-week lifestyle changing program reduces several indicators for metabolic syndrome in overweight adults
}

\author{
Marita S Mecca, Fernando Moreto, Franz HP Burini, Reinaldo C Dalanesi, Kátia CP McLellan and Roberto C Burini*
}

\begin{abstract}
We aim to investigate the effectiveness of a 10-week lifestyle intervention focusing on physical activity and high fiber intake for reducing indicators for metabolic syndrome in overweight-obese individuals. A prospective study of 50 overweight (OW) adults (22 in the general educational group - G1; 28 in the high fiber nutrition group - G2) was performed. Both groups were offered dietary counseling and supervised exercise. Clinical, anthropometric, dietary and plasma biochemical tests were performed at baseline - time 0 (T0) and after 10 weeks - time 1 (T1). Both groups improved their dietary quality, but only G2 presented higher intake of fruit and vegetables (servings/ day), higher plasma $\beta$-carotene levels and a $24 \%$ reduction of MetS incidence. Additionally G2 showed greater reductions in body fat (4\%), and waist circumference (7\%), obesity class III (2\%) and obesity class II (14\%) rate. Lifestyle intervention, including a high dietary fiber intake, improved healthy eating index and decreased body fat composition and plasma lipid concentrations leading to MetS incidence reduction.
\end{abstract}

\section{Introduction}

The metabolic syndrome (MetS) is a complex disorder characterized by abdominal obesity, insulin resistance, hypertension, hypertriglyceridemia and low HDL-c concentration, and inflammation [1]. Four major components identify metabolic syndrome: central obesity, hypertriglyceridemia and low high density lipoprotein cholesterol (HDL-c) concentration, elevated blood pressure and elevated plasma glucose levels [2]. These major components are often associated with decreased insulin sensitivity [3], unhealthy body composition [4], a proinflammatory [5], pro-oxidant [6] and prothrombotic [2] states and a low level of cardio-respiratory fitness [7]. Hence sedentary behavior and obesity are strongly associated with an increased risk for developing metabolic syndrome $[3,8]$.

MetS is associated with severe health complications, such as increased risk of type 2 diabetes and atherosclerotic cardiovascular disease [9] and represents a growing public health problem [10]. Development of the MetS is influenced by genetic as well as environmental

\footnotetext{
* Correspondence: burini@fmb.unesp.br

Department of Public Health - Medical School - Sao Paulo State University -
} UNESP, Brazil factors $[11,12]$. MetS increases the risk of premature death [13-15], therefore, effective and affordable strategies to control the syndrome would benefit the population at risk.

In the western world $\sim 25 \%$ of young to middle-aged adults have MetS [16]. There seem to be strong age dependence in the prevalence of metabolic syndrome, but the incidence rises rapidly within adolescents and middle-aged groups and follows the development of obesity in the general population [17].

Lifestyle modification focusing on improving dietary quality and physical activity is the preferred first-line treatment for the management of metabolic syndrome components and comorbidities. However, attempts to modify lifestyle to improve dietary quality and physical fitness are often unsuccessful due to low compliance. Simpler approaches to diet and physical activity have been under investigation [18].

To date, most researchers agree that overweight and obesity are caused by numerous factors; however, a long-term energy imbalance between intake and expenditure appears to be the primary cause. Hence, limiting energy consumption would be a key objective when weight loss is the goal. Regular physical activity can improve the metabolic profile and the risks of 
cardiovascular diseases and premature mortality. Physical exercises either aerobic interval training or strength training or even a combination of both have beneficial effects on physiological abnormalities associated with MetS [19]. Over the years, much attention has been devoted to prescribing the optimal amount of energy intake to achieve a healthy body weight. Some researchers have looked even further and investigated the possibility that consuming certain dietary factors may aid in weight regulation. Fiber intake is a dietary factor that has received substantial attention by several scientists [20-22].

The present study examined the effectiveness of a 10week lifestyle intervention focusing on physical activity and high fiber intake for reducing indicators for metabolic syndrome in overweight-obese individuals.

\section{Subjects and Methods Study population}

The Lifestyle Changing Program (LCP) that was offered to patients with non-communicable chronic diseases in Botucatu city (São Paulo, Brazil) consisted of supervised exercise and nutritional counseling and has been described elsewhere [23]. The studied subjects were part of subgroup (convenience sample) of participants clinically screened for the lifestyle change program "Mexa-se Pró-Saúde [Move for Health]", in the year of 2006.

A total of 50 overweight-obese individuals $(11 \mathrm{men}$ and 39 women), (Body mass index $=33.0 \pm 5.1 \mathrm{~kg} / \mathrm{m}^{2}$ ) and with a mean age of $50.2 \pm 11.8$ years old were included in this study. This study was conducted in accordance with the Declaration of Helsinki (1964). Subjects gave their written consent to participate in the study, which was approved by the Medical Ethics Committee of Sao Paulo State University (Comitê de Ética em Pesquisa da Faculdade de Medicina da Universidade Estadual Paulista - UNESP).

\section{Study Design}

The study was longitudinal quasi-experimental with evaluations at baseline - time 0 (T0) and after a 10-week of lifestyle intervention based on physical exercises and dietary counseling - time 1 (T1). Participants of the lifestyle changing program were divided in two groups: general education group (G1) of 22 subjects who were given dietary counseling at baseline and physical activity section three times a week; and high fiber nutrition group (G2) of 28 subjects who decided to follow a high dietary fiber intake (30 g/day) along with weekly dietary counseling and physical activity section three times a week. The enrollment for both groups was voluntary. All participants were invited to attend the physical examination at baseline and after 10 weeks. Biochemical data, anthropometric data, and dietary intake were assessed at baseline and T1.

Dietary counseling was provided by a dietitian that met with all participants at baseline to discuss the dietary intervention for both groups. The dietary intervention for the general education group (G1) consisted of general group discussion about benefits of fruit and vegetable intakes and body weight loss.

The dietary intervention for the high fiber nutrition group (G2) consisted of a nutritional counseling group about fiber-rich foods once a week focused on increasing the intake of fruits and vegetables. Participants were given a target number of daily fiber intake of $30 \mathrm{~g}$ [24]. At each group visit with the dietitian participants were given a list and description of whole grain foods to help them identify foods to include in their diet. The weekly group section also discussed ingredients substitution in meals to increase fiber intake through adding fruits and vegetables to the usual recipes and different cooking methods. In addition, participants were encouraged to increase the daily intake of fruit and vegetables, whole grain cereals, legumes, low-fat dairy products, and lean meat, fish or poultry as recommended in the Food Guide for the Brazilian population [25].

\section{Laboratory analyses}

Blood samples were collected by vacuum venous puncture, after a 10 to 12-hour fasting period, and centrifuged to obtain serum and plasma samples which were stored at $-80^{\circ} \mathrm{C}$ until the end of the study. The individuals were previously advised to not perform vigorous physical exercises 24-hours and/or consume alcohol 72hours prior to blood collection. Plasma triglycerides (TG), total cholesterol (Total-c), high-density lipoprotein cholesterol (HDL-c), uric acid (UA), creatinine (Cr) and gamma-glutamyl transpeptidase $(\gamma \mathrm{GT})$ were assayed by dry-chemistry (Systems Vitros chemistry $950 \mathrm{Xr}$ ). Plasma low-density lipoprotein cholesterol (LDL-c) was calculated using the Friedewald equation, $\beta$-carotene $(\beta C)$ and malonildyaldehyde (MDA) were assayed by high-performance liquid chromatography and the highsensitive C-reactive protein (hS-CRP) by chemoluminescense (Immulite, 2000).

\section{Body composition}

Weight, height and waist circumference (WC) were measured with standardized protocols [26]. Body Mass Index (BMI) and waist circumference were evaluated according to the World Health Organization [27]. Body fat percentage (BF\%) was assessed by a bioelectrical impedance device (Biodynamics ${ }^{\circledR}$, model 450, USA).

The percentage of muscle mass (\%MM) was obtained using the Janssen et al., [27] equation and the muscle mass index (MMI) was calculated as MM $(\mathrm{kg}) /$ height $^{2}$. 
Individuals were classified as sarcopenic if their values were below $10.75 \mathrm{~kg} / \mathrm{m}^{2}$ and $6.75 \mathrm{~kg} / \mathrm{m}^{2}$ for men and women, respectively [28].

\section{Dietary intake}

Dietary intake data was assessed using a single 24-hour dietary recall at baseline and T1. The diet was documented by a dietitian, and to obtain precise information, the subjects were asked if that was typical day of intake from them, how often they usually ate during the day, what variety of food was consumed, how the food was prepared, what the serving size was, and what the brand of the food/meal was. Total caloric intake was computed using the Brazilian food tables [29-31]. The Healthy Eating Index (HEI) modified for the Brazilian population was used to assess the quality of the participants' diet [32]. Eight food groups and 12 components to measure the variety and quality of food intake were evaluated.

\section{Physical activity}

All participants were submitted to supervised exercise of 80 minutes, including warm up (20 min) walking (40 $\mathrm{min}$ )/stretching (20 min), $3 \mathrm{x} / \mathrm{wk}$ complemented with 60 $\min (2 \mathrm{x} / \mathrm{wk})$ of strength $(40 \mathrm{~min})$, stretching $(10 \mathrm{~min})$ at a gym [33]. Only participants with frequency of $3 \mathrm{x} /$ wk were included in the study.

\section{Cardio-respiratory fitness}

Cardio-respiratory fitness was determined as maximum oxygen consumption $\left(\mathrm{VO}_{2} \mathrm{max}\right)$ using an electric treadmill (model QMCTM90) according to the Balke protocol [34]. The respiratory indexes was continually measured by an open circuit ergospirometric system (model QMCTM90 Metabolic Cart, Quinton ${ }^{\circledR}$, Bothel, USA) with the Mix-Chamber method and with constant monitoring of the heart and respiratory rates and blood pressures.

\section{Metabolic Syndrome}

MetS was defined using the criteria of National Cholesterol Education Program (NCEP) Expert Panel on Detection, Evaluation, and treatment of High Blood Cholesterol on Adults (ATP-III) when the individual presented three of more of the following factor: abdominal obesity, elevated plasma glucose (considering fasting serum glucose $100 \mathrm{mg} / \mathrm{dL}$ or greater) elevated plasma TG levels, low levels of plasma HDL-c, and high blood pressure [2].

\section{Blood Pressure}

Systolic (SBP) and diastolic (DBP) arterial blood pressure (BP) was evaluated with the individual in the seated position according to the procedures described by the VI Brazilian Guidelines on Arterial Hypertension [35], using properly sized cuffs for arm circumference, considering the width/length proportion of $1: 2$, and the width of the cuff's rubber bag, which should correspond to $40 \%$ of arm circumference, and length, to at least $80 \%$.

\section{Statistical analysis}

Descriptive statistics were performed for the study and continuous variables are presented as means \pm standard deviation (SD). Categorical variables are presented as absolute numbers and percentages. Continuous variables were compared by the independent t-test. Samples were tested for normal distribution (Shapiro Wilk) and groups were compared by either Student's t-test or Wilcoxon Mann Whitney test. The results are discussed based on a significance level of $5 \%(\mathrm{p}<0.05)$.

\section{Results}

Baseline characteristics of participants did not differ significantly between the groups (Table 1). Baseline values and changes in body composition, dietary intake and laboratory analysis are listed in tables 1 to 3 .

Participants in the $\mathrm{G} 2$ had significantly greater reductions for waist circumference $(-5.0 \%$ greater), weight ( $-4.1 \%$ greater), BMI (-4.0\% greater) and Body fat mass $(-3.6 \%$ greater $)$ over the 10 -week study period. Both muscle mass and aerobic capacity (VO2max) were kept similarly throughout the experiment. Only G2

\begin{tabular}{|c|c|c|c|}
\hline & & T0 & T1 \\
\hline \multirow[t]{2}{*}{ Body weight (kg) } & G1 & $85.6 \pm 19.1$ & $86.0 \pm 19.4$ \\
\hline & $\mathrm{G} 2$ & $89.1 \pm 19.4$ & $85.4 \pm 18.7^{a, b}$ \\
\hline \multirow[t]{2}{*}{ BMI $\left(\mathrm{kg} / \mathrm{m}^{2}\right)$} & G1 & $32.1 \pm 5.3$ & $32.2 \pm 5.4$ \\
\hline & $\mathrm{G} 2$ & $33.5 \pm 5.3$ & $32.1 \pm 5.1^{a, b}$ \\
\hline \multirow[t]{2}{*}{ Body fat (\%) } & G1 & $36.7 \pm 9.5$ & $36.5 \pm 9.3$ \\
\hline & $\mathrm{G} 2$ & $38.6 \pm 8.8$ & $37.2 \pm 8.8^{a, b}$ \\
\hline \multirow[t]{2}{*}{ WC (cm) } & G1 & $103.2 \pm 12.7$ & $103.7 \pm 14.0$ \\
\hline & $\mathrm{G} 2$ & $106.7 \pm 14.4$ & $101.4 \pm 14.2^{a, b}$ \\
\hline \multirow[t]{2}{*}{ Muscle Mass (kg) } & G1 & $25.2 \pm 5.9$ & $24.4 \pm 6.1$ \\
\hline & G2 & $25.36 \pm 6.3$ & $26.8 \pm 6.6$ \\
\hline \multirow[t]{2}{*}{$\mathrm{SBP}(\mathrm{mmHg})$} & G1 & $122 \pm 16.0$ & $127 \pm 16.0$ \\
\hline & G2 & $130 \pm 20.5$ & $114 \pm 13.5^{a, b}$ \\
\hline \multirow[t]{2}{*}{ DBP $(m m H g)$} & G1 & $75.0 \pm 4.5$ & $76.5 \pm 11.0$ \\
\hline & $\mathrm{G} 2$ & $86.2 \pm 9.2$ & $77.0 \pm 6.5^{a, b}$ \\
\hline \multirow[t]{2}{*}{$\mathrm{VO}_{2 \max }$} & G1 & $30.8 \pm 8.4$ & $28.6 \pm 10.8$ \\
\hline & G2 & $26.1 \pm 6.4$ & $25.1 \pm 5.7$ \\
\hline
\end{tabular}

Data expressed as mean \pm SD; BMI: body mass index, WC: waist circumference, SBP: Sistolic Blood Pressure, DBP: Diastolic Blood Pressure $\mathrm{VO}_{2 \text { max }}$ : maximum oxygen consumption;

a statistical significance after intervention $(p<0.05)$.

${ }^{b}$ statistical significance between groups $(p<0.05)$. 
Table 3 Blood markers of control (G1) and high dietary fiber (G2) groups at baseline (T0) and after 10 weeks of intervention (T1).

\begin{tabular}{|c|c|c|c|}
\hline & & T0 & $\mathrm{T} 1$ \\
\hline \multirow[t]{2}{*}{ Creatinine (mg/dL) } & G1 & $1.4 \pm 1.8$ & $1.4 \pm 1.1$ \\
\hline & G2 & $0.83 \pm 0.18$ & $0.87 \pm 0.15$ \\
\hline \multirow[t]{2}{*}{$\gamma \mathrm{GT}(\mathrm{U} / \mathrm{L})$} & G1 & $28.4 \pm 11.1$ & $33.4 \pm 25.2$ \\
\hline & G2 & $32.3 \pm 22.5$ & $28.6 \pm 19.5^{a, b}$ \\
\hline \multirow[t]{2}{*}{ Glucose (mg/dL) } & G1 & $99.0 \pm 21.4$ & $101 \pm 18.3$ \\
\hline & G2 & $96.9 \pm 15.0$ & $95.5 \pm 15.5$ \\
\hline \multirow[t]{2}{*}{ Triglycerides (mg/dL) } & G1 & $141 \pm 73.4$ & $150 \pm 77.2$ \\
\hline & G2 & $145 \pm 57.2$ & $129 \pm 55.3^{\mathrm{a}}$ \\
\hline \multirow[t]{2}{*}{ Total Cholesterol (mg/dL) } & G1 & $177 \pm 41.2$ & $181 \pm 42.0$ \\
\hline & G2 & $197 \pm 39.0$ & $182 \pm 33.7^{\mathrm{a}}$ \\
\hline \multirow[t]{2}{*}{ LDL-c (mg/dL) } & G1 & $104 \pm 31.9$ & $106 \pm 34.4$ \\
\hline & G2 & $124 \pm 37.7$ & $112 \pm 30.5^{a}$ \\
\hline \multirow[t]{2}{*}{$\mathrm{HDL}-\mathrm{c}(\mathrm{mg} / \mathrm{dL})$} & G1 & $44.3 \pm 9.8$ & $45.0 \pm 10.6$ \\
\hline & $\mathrm{G} 2$ & $45.6 \pm 11.8$ & $44.2 \pm 10.6$ \\
\hline \multirow[t]{2}{*}{ hsCRP (mg/dL) } & G1 & $0.54 \pm 0.51$ & $0.51 \pm 0.53$ \\
\hline & G2 & $0.5 \pm 0.4$ & $0.40 \pm 0.3$ \\
\hline \multirow[t]{2}{*}{ Uric acid (mg/dL) } & G1 & $5.3 \pm 1.6$ & $5.6 \pm 1.7$ \\
\hline & G2 & $5.1 \pm 1.7$ & $5.0 \pm 1.4$ \\
\hline \multirow[t]{2}{*}{ MDA (mmol/L) } & G1 & $1.1 \pm 0.2$ & $1.0 \pm 0.3$ \\
\hline & G2 & $0.94 \pm 0.28$ & $0.95 \pm 0.23$ \\
\hline \multirow[t]{2}{*}{$\beta$-carotene (mmol/L) } & G1 & $0.5 \pm 0.2$ & $0.5 \pm 0.3$ \\
\hline & G2 & $0.4 \pm 0.1$ & $0.6 \pm 0.3^{a, b}$ \\
\hline
\end{tabular}

Data expressed as mean $\pm \mathrm{SD} ; \gamma \mathrm{GT}$ : gamma-glutamyltranspeptidase; LDL-c: low density lipoprotein cholesterol; HDL-c: high density lipoprotein cholesterol; hsCRP: high-sensitive C-reactive protein; MDA: malonyldialdehyde;

${ }^{a}$ statistical significance after intervention $(p<0.05)$.

${ }^{\mathrm{b}}$ statistical significance between groups $(p<0.05)$.

experienced a significant decrease in blood pressure systolic $(-15.5 \%)$ and diastolic $(-9.5 \%)$ from baseline to post-intervention (Table 1).

The overall pattern of dietary intake improved in both groups but with higher improvements in G2, mainly HEI (31.1\%) and intake of fruit and vegetables $(279 \%)$ (Table 2). The percentage of individuals that reached the recommendation of dietary fiber ( $30 \mathrm{~g} /$ day) after the intervention was $9.0 \%$ in the G1 group and $46.4 \%$ in the G2 group. The amount of $20 \mathrm{~g}$ of dietary fiber per day was reached, after the intervention, for $31.8 \%$ of individuals from G1 and $96.4 \%$ of individuals from G2.

Only participants in the G2 group experienced significant difference in percentage change in plasma $\gamma \mathrm{GT}, \mathrm{TG}$, total-c and LDL-cholesterol, and $\beta$-carotene concentrations from baseline to post-intervention. From those variables G2 differed from G1 in a significantly greater improvements only in plasma $\gamma \mathrm{GT}(-6.12 \%$ greater) and $\beta$-carotene concentrations (43.5\% greater). The Lifestyle Changing Program with or without high dietary fiber intake had no significant effects on plasma glucose, HDL-c, creatinine, hsCRP, MDA and uric acid concentrations (Table 3).
Table 2 Food intake of control (G1) and high dietary fiber (G2) groups at baseline (T0) and after 10 weeks of intervention (T1).

\begin{tabular}{lccc}
\hline & & T0 & T1 \\
\hline HEI (points) & G1 & $83.3 \pm 8.3$ & $84.2 \pm 8.3$ \\
& G2 & $76.9 \pm 15.5$ & $97.2 \pm 11.0^{\mathrm{a}, \mathrm{b}}$ \\
Legumes (servings/day) & G1 & $1.82(0-6.5)$ & $1.11(0-4)$ \\
& G2 & $1.70(0-8.5)$ & $1.77(0-5.5)$ \\
Fruits + vegetables (g/day) & G1 & $240.2(0-842)$ & $260(20-918)$ \\
& G2 & $231(0-937)$ & $539(127-909)^{\mathrm{a}, \mathrm{b}}$ \\
Fruits (servings/day) & G1 & $1.7(0-10.5)$ & $2(0-10)$ \\
& G2 & $1.5(0-10.5)$ & $4(0.5-8.5)^{\mathrm{a}, \mathrm{b}}$ \\
Vegetables (servings/day) & $\mathrm{G} 1$ & $1(0-5)$ & $1(0-5)$ \\
& $\mathrm{G} 2$ & $0.5(0-4)$ & $1.7(0.5-5.5)^{\mathrm{a}, \mathrm{b}}$ \\
Dietary fibers (g/day) & $\mathrm{G} 1$ & $16.1 \pm 7.8$ & $17.1 \pm 9.4$ \\
& $\mathrm{G} 2$ & $15.2 \pm 7.0$ & $32.1 \pm 8.9^{\mathrm{a}, \mathrm{b}}$ \\
Oils (servings/day) & $\mathrm{G} 1$ & $2(0.5-9.5)$ & $1.5(0.5-4.5)$ \\
& $\mathrm{G} 2$ & $1.9(0-9.5)$ & $0.75(0-2.5)^{\mathrm{a}, \mathrm{b}}$ \\
Total energy (kcal/kg BW/day) & $\mathrm{G} 1$ & $16.1(8.6-45.7)$ & $14.1(6.6-45.7)$ \\
& $\mathrm{G} 2$ & $17.6(7.6-38)$ & $17.12(8.7-19.5)$ \\
\hline
\end{tabular}

Data expressed as mean \pm SD or median (min. - max.);

$\mathrm{HEl}$ : healthy eating index;

a statistical significance after intervention $(p<0.05)$.

${ }^{b}$ statistical significance between groups $(p<0.05)$.

The reduction in percent BMI change in the G2 group observed from baseline to post-intervention was associated with less incidence of obesity class III and class II. The 10-week high dietary fiber intake intervention combined with physical activity was associated with a reduction in percent change of MetS incidence from baseline to post-intervention, while no significant change was seen in the general educational group (Figure 1).

\section{Discussion}

This study demonstrated improvements in multiple markers of HEI, body composition and metabolic indicators following a 10-week Lifestyle Changing Program aimed to assist overweight-obese subjects. The lifestyle intervention used in this study is an example of community education strategy, aimed to provide to all participants information and skills to assist them in achieving recommendations for diet and physical activity [36], additionally to participants in G2 it was offered practical strategies to assist in food choices. Because participants were left to choose which dietary behavioral changes they would incorporate into their lifestyles, it was anticipated that these behaviors would be easier to sustain long term. This builds upon well-established principles of health promotion, i.e. by making healthy choices will continue to make those choices [18].

There are clear limitations to the results presented in this study. The main limitation is that subjects on the 


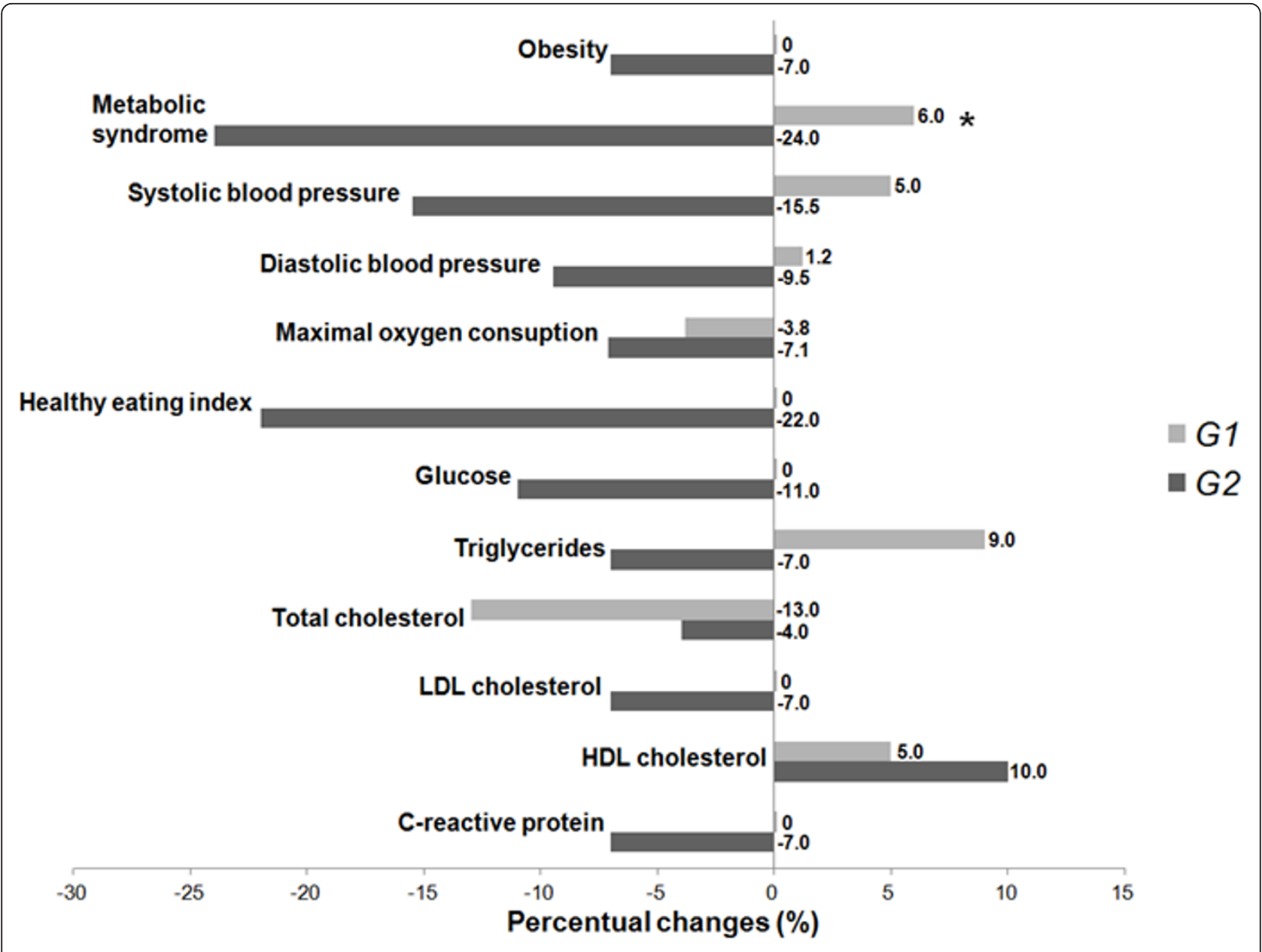

Figure 1 Changes in altered clinical, dietetic and blood markers values after 10-week lifestyle changing program. ${ }^{*} p<0.05$.

high dietary fiber intake chose that intervention. Thus, the effects seen on the high dietary fiber intake may not be due entirely (or at all) to the LCP itself but rather to the fact that the subjects differed - they were more motivated and hence more likely to change their diet and lose weight. There are issues related to the method for collecting dietary data. Diet was assessed using a 24hour dietary recall which has an important limitation for not capture intra-individual variability in food intake. Furthermore, overweight individuals are more likely to under-report their energy intake. Due to this underreporting, it is likely that the current estimates of calories could be underestimated and that dietary components played a larger role in this population's health.

Overweight-obese adults invited to participate in a 10-week high dietary fiber intake in combination with physical activity three times a week improved their HEI keeping stable their body composition, cardiorespiratory fitness and muscle strength. When LCP was associated with high dietary fiber intake there was an even better dietary quality along with reduced body sarcopenia and body adiposity. Furthermore, the high dietary fiber intake lead to a lower blood pressure and better plasma biochemical profile decreasing the incidence of MetS but without significance on markers of insulin resistance, inflammation and oxidative stress.

The adoption of general dietary guidelines, or ad-libitum intake, has been studied and shown promising results $[37,38]$. The free-choice approach to diet and physical activity has been described as a potential method to improve adherence to lifestyle changes [39]. Our dietary component allowed flexibility for individuals to modify their dietary intake, supported by offering practical strategies, such as suggestions, for ingredients substitution in recipes and different cooking methods.

This program may be more applicable to the community setting than individualized diet and exercise programs which require intensive input to facilitate behavioral change. Additionally the group-based approach may be less expensive than individualized strategies. 
Few lifestyle intervention studies [18] have succeeded in counteracting obesity and MetS without controlling energy intake or physical activity, or aiming for large initial weight loss. Smaller behavioral changes, such as increasing dietary fiber intake, are an alternative strategy, and there is evidence that interventions without prescribed weight loss or energy intake targets can improve clinical markers.

The dietary components most strongly related to body composition improvement in the current study was the change in average of foods consumed. Although participants' HEI at baseline was classified as low, a significant greater increase occurred in G2 (20.3 points), compared to G1 (0.9 points). This is likely to reflect the improved dietary quality and better food choices consumed regularly during the intervention.

It is known that as dietary fiber intake increased, energy intake decreased and body weight and body fat decreased as well. Fiber adds to food weight and volume without increasing energy consumption. Thus, more food can be eaten without a commensurate increase in energy intake, or the same total volume of food can be consumed with loss total energy [40]. Total energy was not different between groups and moments. This is probably associated with underreporting of food consumption in obese individuals.

Diet and exercise interventions do not always improve plasma HDL concentrations, as observed by Janssen et al., [41] when plasma HDL concentrations did not improve after a 16-week dietary intervention, with and without aerobic or resistance exercise. Similarly, MetS participants in the Diabetes Prevention Program [42] experienced improvements in all MetS components except plasma HDL concentrations, indicating that plasma HDL concentrations are somewhat resistant to modification through general diet and physical activity changes.

There are few "free-choice" group-based lifestyle intervention studies demonstrating significant changes in BP. The observed reductions $15.5 \%$ in SBP and 9.5\% in DBP exceeded that which might be expected to accompany weight loss in this trial, e.g. a $1 \mathrm{mmHg}$ reductions in SBP for every $2 \mathrm{~kg}$ reductions in body weight [43], and are comparable to those seen after more intensive interventions $[44,45]$.

The relationship between fiber intake and risk of cardiovascular disease has been noted in many studies [46-49]. Although the present study is quite small, the consistency of the findings about the benefits of dietary fiber intake is remarkable.

\section{Conclusion}

Thus short-term LCP including high dietary fiber intake among obese subjects improved HEI and decreased body fat composition and plasma lipid concentrations leading to MetS incidence reduction.

\section{Acknowledgements}

The authors are grateful to FUNDAP (Fundação do Desenvolvimento Administrativo do Estado de São Paulo), CAPES (Coordenação de Aperfeiçoamento de Pessoal de Nível Superior), CNPq (Conselho Nacional de Desenvolvimento Científico e Tecnológico) and GAP (Grupo de Apoio à Pesquisa) of Medical School, São Paulo State University (UNESP).

\section{Authors' contributions}

MSM performed the literature review, conducted the dietary interventions, analyzed body composition and wrote the manuscript. FM collected the blood analyzed the samples and supervised the data analysis. FHPB conducted the medical procedure, supervised the data analysis and reviewed the manuscript. RCD collected and supervised the physical activity and data analysis. KCPM analyzed the data and reviewed the manuscript. $\mathrm{RCB}$ was the mentor of the project, advice of the co-authors and principal investigator. All authors read and approved the final version of the manuscript.

\section{Competing interests}

The authors declare that they have no competing interests.

Received: 23 August 2011 Accepted: 19 January 2012

Published: 19 January 2012

\section{References}

1. Moller DE, Kaufman KD: Metabolic syndrome: a clinical and molecular perspective. Annu Rev Med 2005, 56:45-62.

2. National Cholesterol Education Program: Third report of the National Cholesterol Education Program (NCEP) Expert Panel on Detection, Evaluation, and Treatment of High Blood Cholesterol in adults (Adult Treatment Panel III) final report. Circulation 2002, 106:3143-421.

3. Reaven G: Characteristics of metabolic syndrome. Endocrinol Metab 1995 , 2(Suppl B):37-42

4. Stewart KJ, Bacher AC, Turner K, Lim JG, Hees PS, Shapiro EP, Tayback M Ouyang P: Exercise and risk factors associated with metabolic syndrome in older adults. Am J Prev Med 2005, 28:9-18.

5. Devaraj S, Rosenson RS, Jialal I: Metabolic syndrome: an appraisal of the pro-inflammatory and procoagulant status. Endocrinol Metab Clin North Am 2004, 33:431-53.

6. Hansel B, Giral P, Nobecourt E, Chantepie S, Bruckert E, Chapman MJ, Kontush A: Metabolic syndrome is associated with elevated oxidative stress and dysfunctional dense high-density lipoprotein particles displaying impaired antioxidative activity. J Clin Endocrinol Metab 2004, 89:4963-71.

7. Finley CE, La Monte MJ, Waslien Cl, Barlow CE, Blair SN, Nichaman MZ Cardiorespiratory fitness, macronutrient intake, and the metabolic syndrome: the Aerobics Center Longitudinal Study. J Am Med Assoc 2006, 106:673-97.

8. Saltin B, Helge JW: Metabolic capacity of skeletal muscles and health Ugeskr Laeger 2000, 162:2159-64.

9. Assmann G, Guerra R, Fox G, Cullen P, Schulte H, Willett D, Grundy SM: Harmonizing the definition of the metabolic syndrome: comparison of the criteria of the Adult Treatment Panel III and International Diabetes Federation in United States American and European populations. Am J Cardiol 2007, 99:541-8.

10. Grundy SM, Cleeman II, Daniels SR, Donato KA, Eckel RH, Franklin BA, Gordon DJ, Krauss RM, Savage PJ, Smith SC, Spertus JA, Costa F: Diagnosis and management of the metabolic syndrome: an American Heart Association/National Heart, Lung, and Blood Institute Scientific Statement. Circulation 2005, 112:2735-52.

11. Groop L: Genetics of the metabolic syndrome. Br J Nutr 2000, 83(Suppl 1): S39-48.

12. Szabo DE, Edelenyi F, Goumidi L, Bertraiss S, Philips C, MacManus R, Roche $\mathrm{H}$, Planells $\mathrm{R}$, Lairon D: Prediction of the metabolic syndrome status based on dietary and genetic parameters, using Random Forest. Genes Nutr 2008, 3:173-6. 
13. Gami AS, Witt BJ, Howard DE, Erwin PJ, Gami LA, Somers VK, Montori VM: Metabolic syndrome and risk of incident cardiovascular events and death: a systematic review and meta-analysis of longitudinal studies. J Am Coll Cardiol 2007, 49:403-13.

14. Katzmarzyk PT, Church TS, Blair SN: Cardiorespiratory fitness attenuates the effects of the metabolic syndrome on all-cause and cardiovascular disease mortality in men. Arc Intern Med 2004, 164:1092-97.

15. Lakka HM, Laaksonen DE, Lakka TA, Niskanen LK, Kumpusalo E, Tuomolehto J, Salonen JT: The metabolic syndrome and total and cardiovascular disease mortality in middle-aged men. JAMA 2002, 288:2709-16.

16. Grundy SM, Hansen B, Smith SC Jr, Cleeman JL, Kahn RA: American Heart Association, National Heart, Lung, and Blood Institute, American Diabetes Association - Clinical management of metabolic syndrome: report of the American Heart Association/National Heart, Lung, and Blood Institute/American Diabetes Association conference on scientific issues related to management. Circulation 2004, 109:551-56.

17. Hildrum B, Mykletun A, Hole T, Midthjell K, Dahl AA: Age-specific prevalence of the metabolic syndrome defined by the International Diabetes Federation and the National Cholesterol Education Program: the Norwegian HUNT 2 study. BMC Public Health 2007, 7:220.

18. Pettman TL, Buckley JD, Misan GMH, Coates AM, Howe PRC: Health benefits of a 4-mo groups-based diet and lifestyle modification program for individuals with metabolic syndrome. Obes Res Clin Pract 2009, doi: 10.1016/j.orcp2009.06.002

19. Stensvold D, Tjonna AE, Skang E, Aspenes S, Stolen T, Wisloff U, Stordahl SA: Strength training versus aerobic interval training to modify risk factors of metabolic syndrome. J Appl Physiol 2010, 108:804-10.

20. Burton-Freeman B: Dietary composition and obesity: do we need to look beyond dietary fat? J Nutr 2000, 130:S272-5.

21. Slavin JL: Dietary fiber and body weight. Nutr 2005, 21:411-8.

22. Schulz $M$, Nothlings $U$, Hoffman K, Bergmann MM, Boeing $H$ : Identification of a food pattern characterized by high-fiber and low-fat food choices associated with low prospective weight change in the EPIC. Postdam cohort. J Nutr 2005, 135:1183-9.

23. Portero-McLellan KC, Pimentel GD, Corrente JE, Burini RC: Association of fat intake and socioeconomic status on anthropometric measurements of adults. Cad Saude Colet 2010, 18(2):266-74.

24. I Diretriz Brasileira de Diagnóstico e Tratamento da Síndrome Metabólica. Ara Bras Cardiol 2005, 84:1-28, Suplemento I.

25. Brasil. Ministério da Saúde. Secretaria de Atenção à Saúde: Guia alimentar para a população brasileira: promovendo a alimentação saudável/ Ministério da Saúde, Secretaria de Atenção à Saúde, Brasília: Ministério da Saúde. 2008, 210, (Série A. Normas e Manuais Técnicos)

26. World Health Organization: OBESITY Preventing and managing the global epidemic: report of a WHO Consultation on Obesity. Geneva: WHO; 1998.

27. Janssen I, Heymsfield SB, Baumgartner RN, Ross R: Estimation of skeletal muscle mass by bioelectrical impedance analysis. J App/ Physiol 2000, 89:465-71.

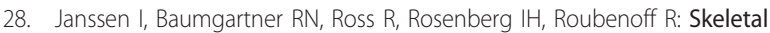
muscle cutpoints associated with elevated physical disability risk in older men and women. Am J Epidemiol 2004, 159:413-21.

29. NEPA/UNICAMP: Tabela brasileira de composição de alimentos. Taco. Versão 1. Campinas; 2004.

30. Instituto Brasileiro de Geografia e Estatística: Tabela de Composição de Alimentos. Rio de Janeiro: 51999.

31. Philippi ST: Tabela de Composição de Alimentos: Suporte para decisão nutricional. São Paulo; $2^{\text {a }} 2002$.

32. Mota JF, Rinaldi AEM, Pereira AF, Maestá N, Scarpin MM, Burini RC Adaptação do Índice de Alimentação Saudável ao Guia Alimentar da População Brasileira. Rev Nutr 2008, 21:545-52.

33. Ratamess NA, Alvar BA, Evetoch TK, Housh TJ, Kibler WB, Kraemer WJ, et al: Progression Models in Resistance Training for Healthy Adults. Med Sci Sports Exerc 2009, 41:687-708.

34. Balke B, Ware R: An experimental study of Air Force personel. U.S. Armed Forces Med J 1959, 10:675-88

35. Sociedade Brasileira de Cardiologia: Sociedade Brasileira de Hipertensão. Sociedade Brasileira de Nefrologia. VI Diretrizes Brasileiras de Hipertensão. Arq Bras Cardiol 2010, 95(1 supl 1):1-51

36. World Health Organization: Global strategy on diet, physical activity, and health. Geneva: WHO; 2004.
37. Kilkkinen A, Heistaros S, Laatikainen T, Janus E, Chapman A, Absetz P, Dunbar J: Prevention of type 2 diabetes in a primary health care setting: interim results from the Greater Green Triangle (GGT) Diabetes Prevention Study. Diab. Res Clin Pract 2007, 76:460-2.

38. Sloth B, Krog-Mikkelsen I, Flint A, Tetens I, Bjorck I, Vinoy S, Elmstahl H, Raben A: No difference in body weight decrease between a lowglycemic-index and a high-glycemic-index diet but reduced LDL cholesterol after 10-wk ad libitum intake of the low-glycemic-index diet. Am J Clin Nutr 2004, 80:337-47.

39. Kohl HW, Dunn AL, Marcus BH, Blair SN: A randomized trial of physical activity interventions: design and baseline data from Project Active. Med Sci Sports Exerc 1998, 30:275-83.

40. Tucker LA, Thomas KS: Increasing total fiber intake reduces risk of weight and fat gains in women. J Nutr 2009, 139:576-81.

41. Janssen I, Fortier A, Hudson R, Ross R: Effects of an energy-restrictive diet with or without exercise on abdominal fat, intermuscular fat, and metabolic risk factors in obese women. Diabetes Care 2002, 25:431-8.

42. Orchand TJ, Temprosa M, Goldberg R, Haffner S, Ratner R, Marcovina S, Fowler S: Diabetes Prevention Program Group. The effect of metformin and intensive lifestyle intervention on the metabolic symdrome: the diabetes prevention program randomized trial. Ann Intern Med 2005, 142:611-9.

43. Chobanian AV, Bakris GL, Black HR, Cushman WC, Green LA, Izzo Jr, Jones DW, Materson BJ, Oparil S, Wright JT Jr, Roccella EJ: Seventh report of the joint national committee on prevention, detection, evaluation, and treatment of high blood pressure. Hypertension 2003, 42:1206-52.

44. Sjostrom CD, Peltonen M, Sjostron L: Blood pressure and pulse pressure during long-term weight loss in the obese: the Swedish obese subjects (SOS) intervention study. Obesity Res 2001, 9:188-95.

45. Stamler J, Rose G, Stamler R, Elliot P, Dyer A, Marmot M: INTERSALT study findings, public health and medical care implications. Hypertension 1989, 14:570-7.

46. Ascherio A, Rimm EB, Giovannucci D, Spiegelman MJ, Stampfer MJ, Willett WC: Dietary fat and risk of coronary heart disease in men: Cohort follow up study in the United States. BMJ 1996, 313:84-90.

47. Rimm EB, Ascherio A, Giovannucci D, Spiegelman MJ, Stampfer MJ, Willett WC: Vegetable, fruit, and cereal fiber intake and risk of coronary disease among men. JAMA 1996, 275:447-451.

48. Rimm EB, Willett WC, Hu FB, Sampson L, Colditz GA, Manson JE, Hennekens C, Stampfer MJ: Folate and vitamin B6 from diet and supplements in relation to risk of coronary heart disease among women. JAMA 1998, 279:359-364

49. Hu FB, Stampfer MJ, Manson JE, Rimm E, Colditz GA, Speizer FE, Hennekens $\mathrm{CH}$, Willett WC: Dietary protein and risk of ischemic heart disease in women. Am J Clin Nutr 1999, 70(2):221-7.

\section{doi:10.1186/1758-5996-4-}

Cite this article as: Mecca et al:: Ten-week lifestyle changing program reduces several indicators for metabolic syndrome in overweight adults. Diabetology \& Metabolic Syndrome 2012 4:1.

\section{Submit your next manuscript to BioMed Central and take full advantage of:}

- Convenient online submission

- Thorough peer review

- No space constraints or color figure charges

- Immediate publication on acceptance

- Inclusion in PubMed, CAS, Scopus and Google Scholar

- Research which is freely available for redistribution 